\title{
PERSPECTIVE
}

\section{Is a one eyed racing driver safe to compete? Formula one (eye) or two?}

\author{
William Westlake
}

\section{Background}

The visual requirements for a competition racing driver's licence as stated by the Confederation of Australian Motor Sport (CAMS) are: a visual acuity of $6 / 9$ or better in each eye, a peripheral visual field of $200^{\circ}$, and functional stereopsis. ${ }^{1}$ The field requirement appears to be based historically on Traquair and Roenne's data concerning the size of the normal visual field. ${ }^{2}$ The required level of stereopsis is undefined and open to interpretation. CAMS rules state that monocularity is an absolute bar to the granting of a licence. ${ }^{1}$

A CAMS medical practitioner examined an applicant whose right eye had been enucleated at age 2 because of a retinoblastoma. The application was successful and in the following season he competed in 24 practice events and races, finishing towards the back of the field, but completing the season with only one incident. In his third race he had a false start and for seven laps failed to see and act on the resulting penalty flags, which were being waved on his normally sighted left side.

Shortly after a second medical examination at the end of the season, he was informed that because of his monocularity his licence was revoked forthwith. Following an unsuccessful appeal, he lodged a complaint in the Human Rights and Equal Opportunities Commission alleging unfair discrimination because of his disability. CAMS argued in defence that he was not reasonably capable of performing the actions required of him in relation to motor racing.

Motor racing is inherently dangerous ${ }^{3}$ and driver vision is critical to the safe operation of a racing car. However, the literature contains no evidence regarding the visual requirements of a racing driver and all the evidence presented to the commission related to driving on the road or simulated road driving. These studies are unhelpful in defining the visual requirements of the domestic road driver, still less those of a racing driver. The outcome measure usually applied in studies relating driving performance to visual performance is crash rate, yet many authors have in the past emphasised the minimal part played by driver vision compared with other factors in the causation of domestic road crashes. ${ }^{4-7}$ The relevance of such studies when extrapolated to the racetrack was a matter of disagreement.

The tribunal was also asked to consider whether the completion of a relatively uneventful season's racing constituted an adequate demonstration of his fitness to compete or whether faster lap times and a higher grid position would increase the risk of a crash resulting from his visual deficit.

This review is a summary of the relevant aspects of monocularity, which consist of six main areas: the reduction in peripheral visual field, the absence of binocular summation, the possibility of supranormal visual function in a monocular individual, the presence of the blind spot, the absence of stereopsis, and temporary visual loss in the remaining eye.

\section{The peripheral visual field}

In the primary position the monocular individual has a $20-40^{\circ}$ peripheral field deficit nasally compared with the temporal side, subject to individual variation, the size of perimetric target used, and the size of the nose. In other positions of gaze the head position also has an important effect. The effect of this peripheral field restriction is variable because some racing cars have cockpit designs that also obstruct the driver's peripheral field.

There is a marked reduction of retinal sensitivity to static luminance targets with increased eccentricity from fixation. ${ }^{2}$ With increased retinal eccentricity there are relatively few ganglion cells; in the periphery they have large receptive fields and each connects with a larger number of photoreceptors than centrally, which are also less densely packed than in the central retina.

The relative resolution of the peripheral field is further reduced by cortical magnification of the fovea, such that $25 \%$ of the striate cortex is devoted to processing the central 2.5 degrees of the visual scene and less than $10 \%$ to the peripheral monocular temporal crescents. ${ }^{8}$ The reduction in sensitivity to most, but not all, visual functions in the peripheral retina is proportional to the reciprocal of the cortical magnification factor at that eccentricity (reviewed by Anstis $^{9}$ ).

In a dynamic situation a reduction in the resolution of the peripheral field is also caused by retinal slip associated with the relative motion of the racing driver's peripheral field. ${ }^{10}{ }^{11}$ The decline in sensitivity of the peripheral field is less for motion perception compared with static targets ${ }^{12}$ and the peripheral acuity should easily be adequate to detect and identify an overtaking car in the far temporal field. Asymmetry exists in the thresholds for many visual functions when the temporal hemifield is compared with the nasal hemifield, the temporal hemifield being more sensitive. ${ }^{12}{ }^{13}$ This may disadvantage the monocular driver who lacks a temporal field on one side.

Humans compensate for their reduction in peripheral retinal sensitivity with saccadic eye movements to refixate the high resolution central retina. ${ }^{9}$ Despite the low sensitivity of the peripheral retina any peripheral blindness would be expected to be of some disadvantage since an object must, firstly, be perceived before a saccade can be directed towards it. Increased head and eye movements could at least partly compensate for a peripheral field deficit but large saccades to the blind side would result in obstruction of the field of view by the nose and alteration of head posture is required to compensate for this. ${ }^{14}{ }^{15}$ The 
velocity of head rotation is determined by the size of rotational movement required but, for large movements measured without wearing a crash helmet, the maximal velocity of head rotation $(250 \%$ s) is of the same order of magnitude as saccadic velocity $\left(400 \%\right.$ s) ${ }^{16}$ It seems unlikely that use of the neck muscles rather than the extraocular muscles to refixate the eyes would significantly delay reception of the visual stimulus.

With regard to the extent of the visual field, a binocular field of $140^{\circ}$ could be assumed to be $70^{\circ}$ on each side, whereas the equivalent monocular field would be $50^{\circ}$ on the nasal side and $90^{\circ}$ on the temporal side. The monocular field would therefore be the equivalent of a binocular field of $100^{\circ}$ on one side and $180^{\circ}$ on the other. In motor racing overtaking is allowed on both sides, and different circuits race clockwise or anticlockwise, so each hemifield should be considered equally important.

It is hard to assess the effect that a monocular driver's peripheral field restriction has on crash rates. Studies indicating increased crash rates or difficulty with driving in glaucoma ${ }^{17} 18$ and retinitis pigmentosa ${ }^{1920}$ are of limited relevance since both diseases cause global depression of the visual field, rather than isolated peripheral field loss and sufferers frequently have a greater degree of visual loss than that found in the healthy monocular driver. ${ }^{19}{ }^{20}$ Glaucoma primarily affects an older population, ${ }^{21}$ and both ageing $^{22}$ and glaucoma ${ }^{23}$ are associated with a deficit in motion detection that would not affect a healthy 40 year old monocular individual. Of many retrospective studies relating peripheral field loss to crash rates in large samples of drivers, the tribunal considered three of the largest. ${ }^{24-28}$ None of these studies addresses the underlying aetiology of the field loss within the populations studied, so the above considerations would equally apply to some of the subjects. One investigation involved 52000 North Carolina drivers and compared the visual field with mileage adjusted crash rates. ${ }^{24}$ The authors were unable to demonstrate a relation between the extent of the peripheral field and crash rates. Another study of 17000 Californian drivers ${ }^{25-27}$ also failed to establish a significant association between peripheral field loss and 3 year crash rates. These findings are surprising, but the perimetric methods used in both studies were non-standard ${ }^{2429}$ and only the lateral extent of the visual field was measured. In the North Carolina study the perimetery was performed in non-standardised lighting conditions by civil servants with only minimal training in perimetery. The North Carolina drivers with a visual field of less than $120^{\circ}$ had a $50 \%$ increase in side impact collisions compared with drivers with more than $160^{\circ}$ field, although the overall crash rate was similar for both groups. It would seem likely that drivers with a restricted peripheral field modify their driving behaviour to compensate for their disability, resulting in a lower crash rate but, because of their blindness, have an increased number of unavoidable side impacts. A number of other authors have suggested that drivers compensate for their visual impairment by modification of their driving behaviour to minimise crash rates. ${ }^{45}{ }^{30-33}$ However, it is not feasible for the visually impaired racing driver to compensate for his or her disability by slowing down and allowing greater safety margins during overtaking and braking if they are to remain competitive.

Another large study relating peripheral field loss to crash rates was undertaken by Johnson and Keltner. ${ }^{28}$ They used modern perimetric methods to examine the visual fields and 3 year crash rates of 10000 drivers. They found that subjects with "severe" binocular field loss had a $100 \%$ increased crash rate compared with normal controls, a figure that has been subsequently confirmed in smaller samples by some investigators ${ }^{33}$ but not others. ${ }^{34}$

\section{Binocular summation}

Apart from a wider peripheral field, binocularity also confers the potential advantages of binocular summation, whereby the quality of vision is better under binocular viewing conditions than viewing with either eye monocularly. ${ }^{35} 36$ This phenomenon is explained in terms of probability summation and neural summation. Probability summation occurs because when using two eyes twice the number of photoreceptors are stimulated at corresponding retinal points within the visual field compared with monocular viewing. Thus, there is increased probability of photoreceptor stimulation for a given light stimulus. Neural summation occurs higher up the visual pathway as a result of additive neural input into binocularly driven cells. Performance is improved in a variety of visual tasks with both eyes open than monocularly, ${ }^{35-43}$ and it has been shown that binocular viewing lowers contrast threshold by up to $40 \% .^{43}$ The degree of binocular summation is related to the complexity of the task $\mathrm{k}^{40}$ and occurs to a lesser degree in the peripheral field. ${ }^{45}$ There is clearly no potential for binocular summation in an enucleated individual, and it occurs very little in the stereoblind. ${ }^{46}$ In subjects with amblyopia binocular summation is absent at the fovea, ${ }^{47}$ and possibly peripherally as well, depending on the severity of the amblyopia. ${ }^{47} 48$

The functional importance of binocular summation in the real world is unclear and some authors have concluded that stereopsis is a more useful advantage of binocularity than summation. ${ }^{42}$

\section{Vision in the enucleated individual}

The loss of an eye may theoretically lead to the development of supranormal vision in the remaining eye, particularly following enucleation in an infant. Although a one eyed person lacks the advantage of binocular summation, they are not subject to the inhibitory influences of binocular rivalry and inhibition. Animal studies have shown that prenatal or early postnatal monocular deprivation results in a reorganisation of the visual cortex, with the majority of cells becoming driven by the remaining eye. ${ }^{49}$ In both humans and animals normal development of the visual pathway consists of initial overproduction and arborisation of ganglion cells followed by selective apoptosis. ${ }^{50}$ Prenatal enucleation can result in a larger than normal number of axons within the remaining optic nerve of rats. $^{52}$ There is conflicting evidence as to the effect that such theoretical considerations have on measures of visual performance.

It has been demonstrated in prenatally enucleated mammals, ${ }^{53} 54$ early enucleated humans, ${ }^{55}{ }^{56}$ and subjects who are functionally monocular ${ }^{57}$ that the contrast sensitivity ${ }^{53-56}$ and vernier acuity ${ }^{57}$ of the undeprived eye are superior to the monocular visual function of normal subjects viewing with their better eye. However, where the binocular visual performance of the normal subjects was measured, it either exceeded ${ }^{415859}$ or was equivalent to ${ }^{55}$ the performance of the one eyed subjects, and when monocular motion detection thresholds were examined, they were found to be equivalent in normal and enucleated subjects. ${ }^{60}$

A case report of unilateral congenital cataract affecting only one of a pair of identical twins revealed no significant differences in the monocular acuity of their better eyes. ${ }^{61}$ The normal twin had a significant improvement in vernier acuity under binocular conditions, and although his binocular acuity exceeded that of his sibling, this difference did not reach statistical significance.

It therefore seems likely that any potential improvement in the vision of the remaining eye of a one eyed person is outweighed by the loss of binocular summation. 


\section{The physiological blind spot}

There are no available data regarding the effect that a paracentral scotoma of an equivalent size to the blind spot would have on driving ability. A blind spot of $6^{\circ}$ diameter results in a scotoma of over 2 metres at 20 metres, but in reality the effective size of such a scotoma is hugely diminished by head movements, relative motion between the eye, and the visual landscape and ocular refixations, which occur on average over three times a second, and up to five times a second in the best performers. ${ }^{62}{ }^{63}$

However, a study of ocular movements under differing driving conditions has demonstrated that when following a car on a familiar route the majority of refixations occur within an area smaller than the blind spot. ${ }^{62}$ Under such conditions if an object such as a hand signal from another driver within the monocular driver's blind spot remained stationary relative to the observer, it would remain unseen for a significant length of time despite ocular refixations. Whether such theoretical considerations have a measurable effect on crash rates is uncertain.

\section{Data relating to the monocular driver}

Of the 10000 drivers studied by Johnson and Keltner, there were 35 drivers with severe monocular field loss. ${ }^{28}$ Their crash and conviction rates were slightly elevated compared with those with a full field, but the differences found did not reach statistical significance $(p>0.2)$ and the authors concluded that the two groups were equivalent. However, their data do imply a greater than $70 \%$ probability of the observed crash and conviction rates in the monocular group being elevated and data for a larger sample of monocular drivers would be needed to identify and quantify the risks associated with monocularity in the domestic driver.

A further report involved the observation of dangerous driving behaviour from an unmarked police car and related this to the driver's visual acuity ${ }^{64}$ The results are not clearly presented but the investigator found that $8 \%(2 / 25)$ of car drivers entering a main road dangerously were one eyed compared with $3.2 \%(27 / 854)$ of control drivers not driving dangerously, and that of drivers observed overtaking dangerously $7.7 \%(6 / 78)$ were one eyed. In this study "one eyed" appears to have been defined as a visual acuity of less than 0.3 (Snellen acuity of 6/20) in the worse eye, at least for the control group. These results do not reach statistical significance and the data would certainly not appear to support the author's contention that "the results gathered show the marked part played by one-eyed drivers as creators of dangerous situations." Another survey found that monocular drivers were overrepresented in a driver rehabilitation programme compared with a general ophthalmic practice, ${ }^{65}$ but it is difficult to draw any valid conclusions concerning the relative abilities of monocular drivers from such data.

In a simulator test at "driving" speeds of $100 \mathrm{~km} / \mathrm{h}$, targets were presented to points within the visual field to which the driver had to respond by braking. Of three long standing monocular drivers tested, one subject responded normally, one showed moderately abnormal responses to some types of target presented on the blind side, while the other subject showed markedly abnormal responses to all target types presented on the blind side. ${ }^{31}$

Wood and Troutbeck ${ }^{66}$ occluded the right eye of 14 young adults, and measured their driving performance on a familiar off road circuit with no other traffic present. No significant differences were found in the drivers' performance with or without occlusion. However, the subjects were given no period of adaptation, so these negative findings would appear to reflect more upon the experimental conditions than the relative driving ability of the monocular driver.

Many authors misquote an article by Kite and King, ${ }^{11}$ incorrectly stating that they found that a gross reduction of the visual field on one side or monocularity is associated with a sevenfold increase in intersectional crashes and pedestrian injuries. The study cited makes no mention of the rates of pedestrian or intersectional injuries for any type of driver.

McKnight and colleagues compared 40 monocular with 40 binocular heavy goods vehicle drivers matched for age and driving experience. ${ }^{67}$ Inclusion criteria for the monocular group are not given and the cause or duration of their monocularity is not stated. Measures of visual function were made and driving performance assessed over a $112 \mathrm{~km}$ test route. The monocular drivers had significantly worse contrast sensitivity, depth perception, low illumination vision, and glare resistance than the binocular drivers and a mean horizontal visual field that was 27 degrees less than the binocular drivers. There were no significant differences in static and dynamic visual acuity, glare recovery, or temporal visual field between the two groups. No significant differences were demonstrated between the two groups in four of five measures of driving performance but the monocular drivers were significantly worse at sign recognition under both day and night driving conditions. Variations in both the visual and driving measures between individuals in either group exceeded the differences noted between the two groups. The authors conclude that "it is possible that the visual deficiencies of the monocular driver might manifest themselves in rare safety related events and that significant differences might have been observed over many thousands of hours of driving." It is unknown whether these deficiencies would manifest themselves over a greatly reduced number of hours driving at increased speed and under the more rigorous conditions of the racetrack.

Another study of heavy goods vehicle drivers ${ }^{68}$ compared 2 year accident and conviction rates of 1202 visually impaired heavy goods vehicle drivers with a sample of unimpaired drivers. Visually impaired drivers were further divided into those with moderate impairment $(<20 / 40$ in the worse eye) or severe impairment $(<20 / 200$ in the worse eye), the acuity in the better eye was at least 20/40 in all cases. The visually impaired drivers had a higher crash frequency, and the severely impaired drivers had more crashes than the moderately impaired drivers. The authors discussed a number of possible confounding factors in their study, though felt that the data provided conditional evidence that visual impairment was associated with an increased crash rate among heavy goods vehicle drivers who fail to meet the US Federal standard of 20/40 vision in each eye.

\section{Stereopsis}

The incidence of stereoblindness in the general population is approximately $2-4 \%$, with $10-15 \%$ having significant difficulties with random dot stereograms ${ }^{6970}$ and $30 \%$ demonstrating abnormalities in more subtle tests of stereopsis ${ }^{69}$ depending on whether the retinal image disparity is uncrossed (closer than fixation) or crossed (beyond fixation). In theory, racing drivers are screened with a cover test to exclude the presence of a squint and normal acuity is required in each eye. If performed correctly these tests would identify the majority of stereoblind individuals. Nevertheless, a few drivers currently racing successfully are likely to be stereoblind and a significant number are likely to have reduced or subtle anomalies of stereopsis. 
Table 1 Summary of different methods of depth perception

\begin{tabular}{ll}
\hline System of depth perception & Substrate \\
\hline $\begin{array}{l}\text { Binocular stereopsis/stereoacuity } \\
\text { Motion parallax }\end{array}$ & $\begin{array}{l}\text { Horizontal retinal image disparity } \\
\text { Changing relations between objects } \\
\text { with observer movement } \\
\text { Increasing retinal image size with } \\
\text { decreased viewing distance } \\
\text { Apparent size of similar objects } \\
\text { The amount of tarmac between the } \\
\text { car in front }\end{array}$ \\
Conerlapping contours & $\begin{array}{l}\text { Concealment of distant objects with } \\
\text { near objects }\end{array}$ \\
Lights and shadows \\
Brightness & $\begin{array}{l}\text { Increased brightness with reduced } \\
\text { viewing distance } \\
\text { Distant objects appear indistinct and } \\
\text { desaturated as a result of dust, haze, } \\
\text { and smog }\end{array}$ \\
Aerial perspective & $\begin{array}{l}\text { Increased convergence and } \\
\text { accommodation with reduced viewing } \\
\text { distance }\end{array}$ \\
\hline
\end{tabular}

The monocular drivers tested by McKnight et $a l^{67}$ had worse skills of depth perception than the binocular drivers, and Gonzalez et $a l^{41}$ found that the depth perception of early enucleated individuals was significantly worse than that of normal children and adults viewing under binocular conditions. The normal subjects tested with one eye occluded and head movement allowed performed as well as the enucleated children; the normal children occluded performed as well as the enucleated children even without head movements allowed. The authors comment only on the accuracy of depth perception and not the subjects' level of confidence in their judgment, which may have been greater in the one eyed group when the normal subjects were occluded. The children had undergone enucleation on average 10 years previously and they had been subjected to surgery under the age of 2 years in all cases.

In the above two investigations monocular depth perception under static conditions was being compared with static binocular depth perception, but the racetrack is a dynamic environment. Dynamic stereopsis correlates poorly with static stereopsis and is reduced with increasing angular velocity. ${ }^{71}{ }^{72}$ The distances and speeds over which stereopsis is operative would suggest that under many circumstances stereopsis would not be useful to the racing driver. But cars race in close proximity to each other and have slow movement relative to one another; furthermore, they are not equipped with brake lights. One reviewer felt that for optimal road safety in everyday traffic, normal stereoscopic vision is essential within a range of 20 metres. $^{72}$

A driver enucleated as an infant is optimally adapted to utilising methods of depth perception other than stereopsis (see Table 1) although the lack of available binocular summation of these monocular cues to depth would be of some disadvantage.

It is unclear whether any theoretical concerns regarding stereopsis are borne out in terms of elevated crash rates on domestic roads. One review article ${ }^{73}$ cites 12 reports published between 1939 and 1969 relating stereopsis to accident rates. Eight of these reported no association, two reported a positive link between stereopsis and crash risk, and two describe mixed results.

More recently, no correlation was found between deficiencies in stereopsis and crash rates among 294 older drivers. ${ }^{74}$ However, an analysis of 1400 drivers who had been involved in a crash in their 70th year demonstrated an increased risk of crash among those drivers with the minimum acuity for driving and reduced stereopsis $(>200 \mathrm{sec}-$ onds arc). ${ }^{75}$ A study of South African lorry drivers demonstrated that 196 accident involved drivers had significantly worse stereoacuity compared with 170 non-accident involved drivers. ${ }^{76}$ Taxi drivers with problems of binocular vision (a stereoacuity $>160$ seconds of arc) had a significantly elevated crash rate compared with those with normal vision. ${ }^{77}$ The same investigators found that truck drivers with reduced stereoacuity were not involved in a greater number of crashes, but had more severe crashes in terms of the number of victims, but this association did not hold for bus drivers with reduced stereoacuity. ${ }^{78}$ The conflicting findings of these two reports may perhaps be partly explained by the differing type and speed of journey undertaken by the various vehicle types.

None of the above studies comment on the aetiology of the stereoscopic deficit. This is relevant because acquired conditions such as unilateral cataract not only reduce stereopsis $^{79-81}$ but also have a detrimental effect upon binocular vision. Unilateral cataract may cause binocular inhibition, the opposite of binocular summation, where the binocular visual acuity and contrast sensitivity are worse than that of the better eye under monocular viewing conditions. This phenomenon occurs in up to $40 \%$ of patients with unilateral cataract. ${ }^{82}$ One would expect such unilateral acquired conditions to cause greater difficulty with driving than an equivalent monocular acuity and stereoscopic deficit caused by long standing amblyopia.

Ideally, racing drivers would be selected on the basis of practical tests of dynamic depth perception rather than insisting upon an undefined level of stereopsis. Since it is possible for a stereoblind individual to perform well at such tests, by its very nature a requirement for stereopsis excludes the stereoblind from participation. Unfortunately, it is simply not feasible to routinely perform tests of dynamic depth perception on prospective applicants.

Physical incapacitation in the monocular individual Racing cars are not equipped with windscreens and despite the use of visors and neck collars, it is possible for foreign material to enter the remaining eye of a monocular competitor during a race. It was postulated that minor ocular disorders such as conjunctivitis, which may lead to epiphora and secondary blepharospasm, would also have a greater effect on the monocular driver's ability to race than a binocular competitor. Other complaints may interfere with the driver's ability to compensate for his visual loss, such as musculoskeletal disorders of the head and neck or ear problems, and these factors may possibly be compounded by negative malingering on the part of the driver. Whether in reality such considerations are of any genuine significance or not was subject to disagreement, and no data are available to resolve the issues.

\section{Conclusions}

On cursory examination the notion of a one eyed racing driver may appear absurd, given the enormous visual input into the driving task and the critical importance of judgments arising from visually based inputs. But $90 \%$ of enucleated adults feel completely adjusted to their monocularity within a year of surgery ${ }^{83}$ and a similar proportion retain the long term ability to perform vision related tasks. ${ }^{84}$ Many individuals feel their major problem is employment discrimination. ${ }^{83}$ An adult enucleated as an infant would be optimally adjusted to his/her monocularity and Tychsen talks of the skills of one eyed individuals in performing tasks that are believed to require precise degrees of stereopsis, citing highly competent one eyed surgeons and aviators as examples. ${ }^{85}$ In this case we have proof that it is possible for the one eyed individual to participate as a racing driver without major incident for at least one season. Certainly the driver presented here had no doubts about his own ability to safely handle a racing car, and neither did the ophthalmologist advising him. 
However, one should not get carried away with such subjective inferences. It is beyond dispute that the one eyed individual has deficiencies in the extent of the central and peripheral field, binocular depth perception, and the ability to maintain vision under temporary blindness in one eye. In many instances, highly effective adaptive strategies may be learned to largely compensate for these deficiencies, ${ }^{86}$ but some degree of disability still remains. The functional significance of this remaining disability is open to debate. In situations where people are operating at the limits of human sensory ability, and where a misjudgment based on visual input may have serious consequences for the individual concerned as well as others around them, CAMS considers it is reasonable to exclude the monocular individual from participation.

As antidiscriminatory laws become increasingly sophisticated, visual requirements for occupations ${ }^{87}$ or other activities will come under greater scrutiny. Ophthalmologists who are called upon to advise on the visual requirements for any activity should be aware that their recommendations are likely to be critically examined by their colleagues, the participants to whom they apply, and their legal advisers. Any visual standard has to be justified not only to the visually impaired who are debarred from participation but also to the potential victim harmed as a result of a participant's visual disability.

Financial declaration: The author has in the past been a paid adviser to the Confederation of Australian Motor Sport.

\section{WILLIAM WESTLAKE}

The McCusker Glaucoma Unit, The Lions Eye Institute, Verdun Street, Nedlands 6009, Western Australia

westlake@networx.net.au

1 Confederation of Australian Motor Sport. CAMS Medical standards. Melbourne: CAMS Ltd, 1997:20.

2 Traquair HM. An introduction to clinical perimetery. 3rd ed. London: $\mathrm{H}$ Kimpton, 1938:1-16.

3 Chesser TJ, Norton SA, Nolan JP, et al. What are the requirements for medical cover at motor racing circuits? Injury 1999;30:293-7.

4 Hills BL. Vision, visibility and perception in driving. Perception 1980;9:183216.

5 Cashell GTW. Visual functions in relation to road accidents. Injury 1972;2: 8-10.

6 Byrnes VA. Visual factors in automobile driving. Trans Am Ophthalmol Soc 1962;60:60-83.

7 North RV. The relationship between the extent of visual field and driving North RV. The relationship between the extent of visual fie
performance-a review. Ophthal Physiol Opt 1985;5:205-10.

performance-a review. Ophthal Physiol Opt 1985;5:205-10.
8 Horton JC, Hoyt WF. The representation of the visual field in human striate cortex. Arch Ophthalmol 1991;109:816-24.

9 Anstis S. Picturing peripheral acuity. Perception 1998;27:817-25.

10 Brown B. Resolution thresholds for moving targets at the fovea and in the peripheral retina. Vis Res 1972;12:293-303.

11 Kite CR, King JN. A survey of the factors limiting the visual fields of motor vehicle drivers in relation to minimum visual fields and visibility standards. Br F Physiol Opt 1961;18:85-107.

12 Fahle M, Werhahn C. Motion perception in the peripheral visual field. Graefes Arch Clin Exp Ophthalmol 1991;229:430-6.

13 Sample PA, Irak I, Martinez GA, et al. Asymmetries in the normal short wavelength visual field: implications for short-wavelength automated perimetry. Am $\mathcal{7}$ Ophthalmol 1997;124:46-52.

14 Marotta JJ, Perrot TS, Nicolle D, et al. The development of adaptive head movements following enucleation. Eye 1995;9:333-6.

15 Goltz HC, Steinbach MJ, Gallie BL. Head turn in one eyed and normally sighted individuals during monocular viewing. Arch Ophthalmol 1997;115: 748-50.

16 Land MF. Predictable eye-head coordination during driving. Nature 1992;359:318-20.

17 Parrish RK, Gedde S, Scott IU, et al. Visual function and quality of life among patients with glaucoma. Arch Ophthalmol 1997;115:1447-55.

18 Foley D, Wallace R, Eberhard J. Risk factors for motor vehicle crashes amongst older drivers in a rural community. I Am Geriatr Soc 1995;43:776-82.

19 Fishman GA, Anderson RJ, Stinson L, et al. Driving performance of retinitis pigmentosa patients. Brf Ophthalmol 1981;65:122-6.

20 Szlyk J, Alexander K, Severing K, et al. Assessment of driving performance in patients with retinitis pigmentosa. Arch Ophthalmol 1992;110:1707-13.

21 Mitchell P, Smith W, Attebo K, et al. Prevelance of open angle glaucoma in Australia: The Blue Moutains Eye Study. Ophthalmology 1996;106:1661-9.

22 Willis A. Anderson SJ. Effects of glaucoma and ageing on photopic and scotopic motion perception. Invest Ophthalmol Vis Sci 2000;41:325-35.

23 Silverman SE, Trick GL, Hart WM. Motion perception is abnormal in primary open angle glaucoma and ocular hypertension. Invest Ophthalmol Vis Sci 1990;31:772-9.

24 Council F, Allen J. A study of visual fields of North Carolina drivers and their relationships to accidents. North Carolina: Highway Safety Research Centre University of North Carolina, 1974.
25 Burg A. Vision and driving: a report on research. Human Factors 1971;13:79-87.

26 Burg A. The relationship between vision test scores and driving record: general findings. Department of Engineering, University of California Report $67-24,1967$

27 Hills BL, Burg A. A reanalysis of California driver vision data: general findings. Crowthorne Berkshire: Transport and Road Research Laboratories Report no LR768, 1977.

28 Johnson C, Keltner J. Incidence of field loss in 20000 eyes and its relationship to driving performance. Arch Ophthalmol 1983;101:371-5.

29 Burg A. Lateral visual field as applied to age and sex. F Appl Psych 1968;52: $10-15$.

30 Owsley C, McGwin G. Visual impairment and driving. Surv Ophthalmol 1999;43:535-55.

31 Lovsund P, Hedin A, Tornros J. Effects on driving performance of visual field defects: a driving simulator study. Acc Anal Prev 1991;23:331-42.

32 Szlyk JP, Seiple W, Viana M. Relative effects of age and compromised vision on driving performance. Human Factors 1995;37:430-6.

33 Ball K, Owsley C, Sloane ME, et al. Visual attention problems as a predictor of vehicle crashes in older drivers. Invest Ophthalmol Vis Sci 1993;34:311023.

34 Ivers R, Mitchell P, Cumming R. Sensory impairment and driving: the Blue Mountains eye study. Am F Pub Health 1999;89:85-7.

35 Horowitz MW. An analysis of the superiority of binocular over monocular visual acuity. F Exp Psychol 1949;39:581-96.

36 Jones RK, Lee DN. Why two eyes are better than one. The two views of binocular vision. $\mathcal{F}$ Exp Psych: Human Perception and Performance 1981;7:30-40.

37 Rose D. Monocular vs binocular contrast thresholds for movement and pattern. Perception 1978;7:195-200.

38 Pardhan S, Rose D. Binocular and monocular detection of Gabor patches in binocular two-dimensional noise. Perception 1999;28:203-15.

39 Simmons DR, Kingdom FA. On the binocular summation of chromatic contrast. Vis Res 1998;38:1063-71.

40 Frisen L, Lindblom B. Binocular summation in humans: evidence for a hierarchic model. F Physiol 1988;402:773-82.

41 Gonzalez EG, Steinbach MJ, Ono H, et al. Depth perception in humans enucleated at an early age. Clin Vis Sci 1989;4:172-7.

42 Blake R, Fox R The psychophysical inquiry into binocular summation. Perception and Psychophysics 1973;14:161-85.

43 Campbell FW, Green DG. Monocular versus binocular visual acuity. Nature 1965;208:191-2.

44 Wehrhahn C, Westheimer G, Abulencia A. Binocular summation in temporal-order detection. F Opt Soc Am A-Opt Image Sci. 1990;7:731-2.

45 Pardhan S. A comparison of binocular summation in the peripheral visual field in young and older patients. Curr Eye Res 1997;16:252-5.

46 Lema SA, Blake R. Binocular summation in normal and stereoblind humans. Vis Res 1977;17:691-5.

47 Pardhan S, Whitaker A. Binocular summation in the fovea and peripheral field of anisometropic amblyopes. Curr Eye Res 2000;20:35-44.

48 Sireteanu R, Fronius M, Singer W. Binocular interactions in the peripheral visual fields of humans with strabismic and anisometropic amblyopia. Vis Res 1981:21:1065-74.

49 Blakemore C, Garey LJ, Vital-Durand F. The physiological effects of monocular deprivation and their reversal in the monkey's visual cortex. $f$ Physiol 1978;283:223-62.

50 Provis JM, Van Driel D, Billson F, et al. Human fetal optic nerve: overproduction and elimination of retinal axons during development. $\mathcal{F}$ Comparative Neurol 1985;238:92-100

51 Rakic P, Riley KP. Overproduction and elimination of retinal axons in the fetal rhesus monkey. Science 1983;219:1441-4.

52 Hsiao CF, Fukuda Y. Plastic changes in the distribution and soma size of retinal ganglion cells after neonatal monocular enucleation in rats. Brain Res 1984;300:1-12.

53 Bisti B, Trimarchi C. Visual performance in behaving cats after prenatal unilateral enucleation. Proc Natl Acad Sci USA 1993;90:11142-6.

54 Heywood CA, Silveira LCL, Cowey A. Contrast sensitivity in rats with increased or decreased numbers of retinal ganglion cells. Exp Brain Res 1988;70:513-26.

55 Nicholas JJ, Heywood CA, Cowey A. Contrast sensitivity in one eyed subjects. Vis Res 1996;36:175-80

56 Reed MJ, Steeves JK, Steinbach MJ, et al. Contrast letter thresholds in the non affected eye of strabismic and unilateral eye enucleated subjects. Vis Res 1996;36:3011-18.

57 Freeman RD, Bradley A. Monocularly deprived humans: non deprived eye has supranormal vernier acuity. F Neurophysiol 1980;43:1645-53.

58 Reed MJ, Steeves JK, Steinbach MJ. A comparison of contrast letter thresholds in unilateral eye enucleated subjects and binocular and monocular control subjects. Vis Res 1997;37:2465-9.

59 Gonzalez EG, Steinbach MJ, Ono H, et al. Vernier acuity in monocular and binocular children. Clin Vis Sci 1992;7:257-61.

60 Bowns L, Kirshner L, Steinbach M. Hemifield relative motion bias in adults monocularly enucleated at an early age. Vis Res 1994;34:3389-95.

61 Johnson CA, Post RB, Chalupa LM, et al. Monocular deprivation in humans: a study of identical twins. Invest Ophthalmol Vis Sci 1982;23:135-6.

62 Mourant R, Rockwell T. Mapping eye movement patterns to the visual scene Mourant R, Rockwell T. Mapping eye movement patterns to the
in driving: an exploratory study. Human Factors 1970;12:81-7.

63 Crundall D, Underwood G, Chapman P. Driving experience and the functional field of view. Perception 1999;28:1075-87

64 Leismaa $M$. The influence of driver's vision in relation to his driving ability. Optician 1973;166:10-13

65 Keeney AH. Ophthalmic pathology in driver limitation. Trans Am Acad Ophthal Otolar 1968;72:737-40.

66 Wood J.M, Troutbeck R. Effect of visual impairment on driving. Human Factors. 1994;36:476-87.

67 Mc Knight AJ, Shinar D, Hilburn B. The visual and driving performance of monocular and binocular heavy duty truck drivers. Acc Anal Prev 1991;23: 225-37.

68 Rogers PN, Janke MK. Performance of visually impaired heavy-vehicle operators. F Saf Res 1992;23:159-70

69 Richards W. Stereopsis and stereoblindness. Exp Brain Res 1970;10:380-8.

70 Julesz B. Foundations of cyclopean perception. Chicago: University of Chicago Press, 1971:217.

71 Zinn WJ, Solomon H. A comparison of static and dynamic stereoacuity. $\mathcal{F}$ Am Opt Ass 1985;56:712-15. 
72 Sachsenweger M, Sachsenweger U. Stereoscopic acuity in ocular pursuit of moving objects. Doc Ophthalmol 1991;78:1-133.

73 Davison PA. The role of drivers vision in road safety. Lighting Res Technol 1978;10:125-37.

74 Owsley C, Ball K, McGwin G, et al. Visual processing and risk of crash amongst older adults. $\mathcal{F} A M A$ 1998;279:1083-8.

75 Gressett JA, Meyer FM. Risk of accidents among elderly car drivers with visual acuity equal to $6 / 12$ or $6 / 15$ and lack of binocular vision. Ophthal Physiol Opt 1994;14:33-7.

76 Humphriss D. Three South African studies on relation between road accidents and drivers' vision. Ophthalmic Physiol Opt 1987;7:73-9.

77 Maag U, Vanesse C, Dionne G, et al. Taxi drivers' accidents: how binocular vision problems are related to rate and severity in terms of the number of victims. Acc Anal Prev 1997;29:217-24.

78 Laberege-Nadeau C, Dionne G, Maag U, et al. Medical conditions and the severity of commercial drivers road accidents. Accid Anal Prev 1996:28:43 51 .

79 Laidlaw A, Harrad R. Can second eye cataract surgery be justified? Eye 1993;7:680-6.
80 Laidlaw DAH, Harrad RA, Hopper CD, et al. Randomised trial of effectiveness of second eye cataract surgery. Lancet 1998;352:925-9.

81 Kwapiszeski BR, Gallagher CC, Holmes JM. Improved stereoacuity: a indication for unilateral cataract surgery $\mathcal{F}$ Cat Ref Surg 1996;22:441-5.

82 Taylor RH, Misson G, Mosely M. Visual acuity and contrast sensitivity in cataract: summation and inhibition of visual performance. Eye 1991;5:705-

83 Lindberg JV, Tillman WT, Allara DR. Recovery after loss of an eye. Ophthalmol Plast Recon Surg 1988:4:135-8.

84 Edwards MG, Schachat AP. Impact of enucleation for choroidal melanoma on the performance of vision-dependent activities. Arch Ophthalmol 1991;109:519-21.

85 Tychsen L. Binocular vision. In: Adlers physiologoy of the eye. 9 th ed. St Louis: Mosby, 1992:784.

86 Godber G. Dealing with the disadvantaged. Living with one eye. BMf 1981; 282:2042-3.

87 Adams GGW, Karas MP. Effect of amblyopia on employment prospects. $B r$ f Ophthalmol 1999;83:380.

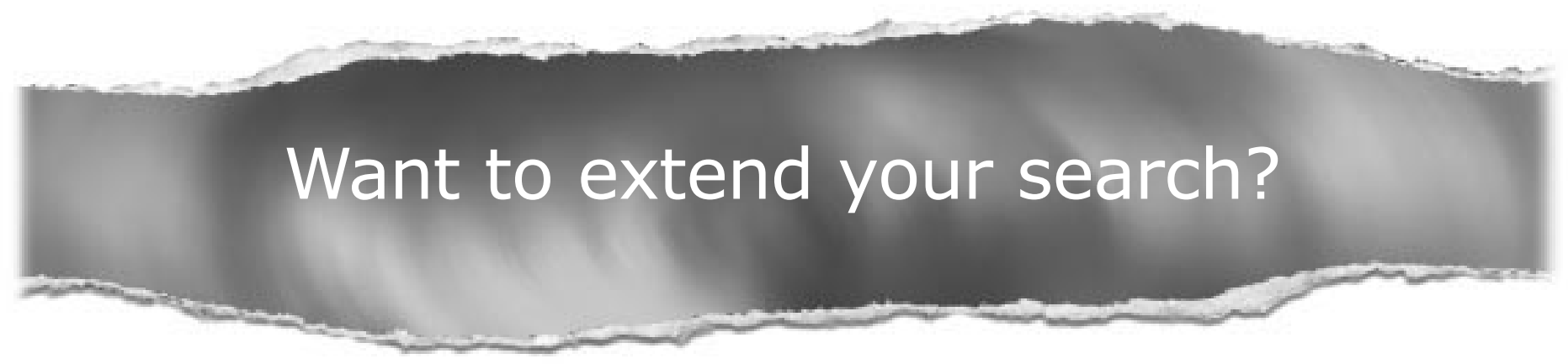

Cross journal searching

If you can't find what you are looking for in the British Journal of Ophthalmology you can extend your search across many of the more than 200 journals available for selection. You can restrict your search to specific subject areas (eg, clinical medicine, basic research), or select specific journals, or search all available titles.

\section{www.bjophthalmol.com}

